\title{
Formação dos profissionais da educação: papéis entrelaçados
}

\author{
Formación de los profesionales de la educación: papeles entrelazados
}

Education professionals training: interlaced papers

Eliane Lima Piske ${ }^{1}$

Sabrina Meirelles Macedo ${ }^{2}$

Angela Adriane S. Bersch ${ }^{3}$

Pamela Saraiva Miranda ${ }^{4}$

Lissete Torres Arévalo 5

Narjara Mendes Garcia ${ }^{6}$

\begin{abstract}
Resumo
Nas circunstâncias de incertezas que assolam o país, nós educadores(as) ambientais precisamos lutar-resistir e as rodas dialógicas são ótimas oportunidades para defender nossos direitos. Não podemos esquecer que precisamos estar dispostos a vivenciar sempre o novo e a (re)pensar as velhas ações pela e com a alteração de mudanças que precisam ser e estar entrelaçados aos papéis que são exercidos na educação, sendo os objetivos do artigo. $\mathrm{Na}$ conjuntura atual escrever um relato de experiência é um grande desafio, mas não poderíamos deixar de registrar. Já que fomos e somos privilegiadas por contar com uma educação pública, de qualidade e emancipatória, resultados que foram defendidos no artigo. Na presente discussão rompemos com as fragmentações ao apresentar as atuações pelos papéis dos profissionais da educação.
\end{abstract}

\footnotetext{
${ }^{1}$ Doutoranda do Programa de Pós-Graduação em Educação Ambiental pela Universidade Federal do Rio Grande (PPGEA/FURG); Bolsista CAPES; Rio Grande/RS; Brasil; e-mail e.nanny@ hotmail.com

${ }^{2}$ Doutoranda pelo Programa de Pós-Graduação em Educação Ambiental da Universidade Federal do Rio Grande (PPGEA/FURG); bolsista CAPES; Rio Grande/RS; Brasil; email sabrinameirelles @ hotmail.com

${ }^{3}$ Doutora em Educação Ambiental e professora do Instituto de Educação- IE/FURG; Rio Grande/RS; Brasil; email angelabersch@gmail.com

${ }^{4}$ Mestranda do Programa de Pós-Graduação em Educação Ambiental da Universidade Federal do Rio Grande (PPGEA/FURG); Rio Grande/RS; Brasil; e-mail ms.pamelasaraiva@ gmail.com

${ }^{5}$ Doutoranda pelo Programa de Pós-Graduação em Educação Ambiental da Universidade Federal do Rio Grande (PPGEA/FURG); bolsista CAPES; Rio Grande/RS; Brasil; e-mail lissettetorresarevalo@ gmail.com

${ }^{6}$ Doutora em Educação Ambiental e professora do Instituto de Educação- IE/FURG; Rio Grande/RS; Brasil; email narjaramg@gmail.com
} 
Palavras-Chave: profissionais, formação, papéis.

\title{
Resumen
}

En las circunstancias de incertidumbres que asolan el país, los educadores ambientales necesitamos lucharresistir y las ruedas dialógicas son óptimas oportunidades para defender nuestros derechos. No podemos olvidar que necesitamos estar dispuestos a vivir siempre lo nuevo y (re)pensar las viejas acciones por la y con la alteración de cambios que necesitan ser y estar entrelazados a los papeles que se ejerce en la educación, siendo estos los objetivos del artículo. En la coyuntura actual escribir un relato de experiencia es un gran desafío, pero no podríamos dejar de registrarlo ya que fuimos y somos privilegiados por contar con una educación pública, de calidad y emancipadora, estos resultados fueron defendidos en el artículo. En la presente discusión rompemos con las fragmentaciones al presentar las actuaciones por los papeles de los profesionales de la educación.

Palabras claves: profesionales, formación, papeles.

\begin{abstract}
In the uncertainties circumstances that plague the country, we, environmental educators need to fight-resist and the dialogical wheels are optimal opportunities to defend our rights. We must not forget that we must be willing to always experience the new and re-think old actions for and with the changes that need to be and be intertwined with the roles that are exercised in education, being the objectives of the article. In the present conjuncture writing an account of experience is a great challenge, but we could not fail to register. Since we were and are privileged to count on a public education, of quality and emancipatory, results that were defended in the article. In the present discussion we break with the fragmentations when presenting the performances by the roles of the education professionals.
\end{abstract}

Keywords: professionals, training, roles.

\section{Introdução}

Somos sujeitos históricos e permeados pelas vivências e as experiências, e, é na formação permanente que nós educadores (re)significamos e compartilhamos os conhecimentos. Não podemos e não devemos esquecer que precisamos estar dispostos a vivenciar sempre o novo e a (re)pensar as velhas ações pela e com a alteração de mudanças que precisam ser e estar entrelaçadas aos papéis que são exercidos na educação, sendo os objetivos do artigo. Ao propor a discussão pretendemos romper com as fragmentações das práticas educativas e mobilizar as atuações dos(as) educadores(as) pelas competências profissionais.

Na circunstância política, socioeconômica e ambiental de extinções, por exemplo: a gestão pública da Educação Ambiental, dos organogramas dos ministérios do Meio Ambiente e da Educação, dentre outras incertezas que assolam o país é um desafio escrever um relato de experiência. Conforme já defendia Freire (2014), precisamos falar e assumir a palavra ao lutar. E é exatamente isso que, almejamos ao escrever o relato de experiência no momento atual. Nós somos a educação pública! Calma, vamos explicar: é que ao escrever sobre os 
papéis dos profissionais de educação também referimo-nos a nós, pois fazemos, uma vez que sempre estudamos em escolas públicas, em universidades federais e continuamos no Programa de Pós-Graduação em Educação Ambiental pela Universidade Federal do Rio Grande (PPGEA/FURG). No decorrer do artigo serão apresentados outros argumentos para a defesa desta constatação.

\section{Metodologia}

$\mathrm{Na}$ conjuntura política e econômica que perpassa o país escrever um relato de experiência é uma enorme responsabilidade, já que fomos e somos felizes por contar com uma educação pública, de qualidade e emancipatória, resultados que serão defendidos na proposta. Somos privilegiadas por contar com uma educação pública que foi firmada pelo diálogo com um grande mestre, Paulo Freire. "A nossa convicção é a de que, quanto mais cedo comece o diálogo, mais revolucionário será" (FREIRE, 2014, p. 172).

O procedimento adotado para a elaboração do artigo foi um relato de experiência escrito pelas mãos de educadoras ambientais. E, embora tenham cursado a graduação em anos diferentes, todas nós encontramos na ousadia em Freire as possibilidades para a formação docente, somos o legado freiriano. Sendo que, todas nós frequentamos escolas públicas, desde o ensino básico até a vaga no ensino superior e o tão sonhado ingresso na Pós-Graduação, ambas as educadoras ambientais ingressaram no Programa de Pós-Graduação em Educação Ambiental pela Universidade Federal de Rio Grande- PPGEA/FURG. Nossa trajetória foi marcada pelo encontro no PPGEA/FURG, profissionais da educação exercendo papéis diferentes: uma doutora/orientadora, uma doutora, três doutorandas e outra mestranda.

O artigo é um estudo que pretende mover e instigar a sempre buscar mais, como diria Freire (2011) buscar o inédito-viável pela nossa trajetória, que foi alicerçada pela base teórica freiriana. Os olhares atentos frente aos papéis dos profissionais da educação fortalecem esperançosamente ações pela base dialógica e em rodas. As rodas ou os círculos de culturas rompem com a disposição da sala de aula em fileiras. Nós defendemos que as rodas de diálogo são um método indispensável na sala de aula ou em qualquer ambiente para (re)pensar as atuações.

As rodas são oportunidades para falar com os educandos e os educadores, todos juntos. Nós, somos educadoras ambientais que aproveitamos essa oportunidade dialógica para 
a docência, somos educadoras por escolha, nós defendemos a educação pública pela relação de pertencer ao ser, estar e lutar pelo ensino de qualidade. Nossa defesa é que Paulo Freire continue vivo ao ser e fazer parte da educação brasileira, embora cientes que ele está presente nos demais países.

$\mathrm{O}$ artigo estabelece um diálogo com Paulo Freire ao consolidar um relato de experiência com os papéis dos(as) educadores(as) ambientais pela formação permanente ser pública e de qualidade para todos, nós acreditamos e defendemos a educação pública! O engajamento, a luta e a audácia de Freire foram propulsores de uma sensibilização que perpassa o centenário pela e com a ação que faz e é a diferença na educação. Para o legado freiriano permanecer vivo, dependerá da nossa luta ao continuar exercendo o que aprendemos. Nesta perspectiva, iremos apresentar os resultados e as discussões sobre os papéis dos(as) professores(as) de educação física, de pedagogos(as) e dos(as) historiadores(as) encharcados(as) em Freire.

\section{Resultados e discussão}

Apresentar o referencial teórico freiriano (1985/2011/2014) entrelaçado com a justificativa, o procedimento e os resultados alcançados pelos objetivos que foram consolidados com o relato de experiência foi a maneira alcançada para evidenciar sobre a luta pela defesa da educação pública. Precisamos fazer-resistir ao que é posto como algo final, por exemplo, as extinções da Educação Ambiental. Como já mencionado somos da educação pública e estamos nela por acreditar na educação como as possibilidades de mudanças para o bem-estar social e não pela ascensão socioeconômica. Nós somos educadoras por escolha, nós somos professoras não por acaso, mas pelo privilégio de estudar e ingressar na universidade e aproveitar as oportunidades ao fazer-resistir pelo mediar pedagógico na educação.

Para apresentar os resultados, vamos responder a uma questão inicial: quais são os papéis dos profissionais da educação? Vamos começar pelos pedagogos, posteriormente pelo historiador, após pelo professor de educação física. Por fim, apresentar o entrelace de ambos os papéis na educação. Ser pedagogo vem historicamente se modificando com o tempo, se fôssemos pensar um século atrás, ser pedagogo era aquele que acompanhava as crianças, faziam as lições em casa. Esse era o papel do pedagogo há um século. A (trans)formação de ser pedagogo foi se modificando com os períodos, provavelmente há dez anos ainda vamos 
ter a (re)construção dos pedagogos não por identidade, mas, profissional. Essas mudanças têm relação com a nossa postura enquanto, profissionais.

A educação é um processo em permanente constituição e (re)significação: entra em cena os(as) historiadores(as), que apontam que as mudanças educacionais e de formação docente estão inseridas em um determinado contexto histórico e cultural, e busca atender as demandas de uma determinada sociedade, atendendo também aos interesses de determinados grupos sociais. Agora, vamos apresentar o papel do professor de Educação Física. A Educação Física tem uma repercussão significativa na vida do educando. Ela que no seu bojo desenvolve as práticas corporais, a cultura corporal, as questões da corporeidade, etc. sem, contudo, dissociar o corpo e a mente. Ela os considera como uma unidade, ou seja, o ser humano na sua totalidade.

Atingiu o momento de mobilizar sobre os papéis entrelaçados dos profissionais de educação. Será que vamos continuar nos definindo como aqueles profissionais que vão ser sempre desvalorizados, em termos de salários, de políticas públicas, dentre outras. Nossa defesa é que não! Nós lutamos ao mobilizar e queremos apresentar que escolhemos a profissão professor(a) por opção, foi nossa escolha! Obviamente, cientes que ainda somos desvalorizados(as), mas buscamos ao ser a diferença que almejamos ao lutar por políticas públicas e por salários dignos a categoria. Não podemos esquecer: estamos em constituição mesmo tendo o título, a formação, pois ser pedagogo é um processo em permanente (trans)formação educadora. O pedagogo soma 4 horas diárias com os educandos e no final do ano letivo são 800 horas com eles. Mais uma vez, podemos perceber nossa responsabilidade ao fazer da educação. Exatamente como os historiadores e os professores de educação física.

Professores de educação física, pedagogos e historiadores têm conhecimentos sobre a educação, as políticas educacionais, a história da educação, as metodologias de ensino, as práticas educativas, dentre outros. Como salienta Freire: "para mim que me situo entre os que não aceitam a separação impossível entre prática e a teoria, toda prática educativa implica uma teoria educativa" (FREIRE, 2011, p. 21). Ser professor de educação física, pedagogo e historiador é perceber e atuar para que os papéis sejam dialógicos e em constante construção e (re) significação educadora. Somos profissionais da educação, temos conhecimentos sobre vários elementos e estamos sempre em permanente formação, somos professores de educação física, pedagogos(as) e historiadores(as), profissionais da educação. 
Nós profissionais da educação temos saberes conceituais, das experiências construídas ao longo do curso de Educação Física, Pedagogia e/ou de História e a partir de outros elementos da educação. Sendo assim, precisamos estar sempre avaliando nossa atuação docente, assim como refletir sobre nossa atuação/prática, como diria Freire. "[...] a práxis, porém, é ação e reflexão dos homens sobre o mundo para transformá-lo" (FREIRE, 2014, p. 52). Não planejamos a prática essa é uma competência do(a) professor(a) de Educação Física, do Pedagogo(a) e do Historiador(a), sendo assim estabelecer essa organização é necessária e indispensável para a compreensão dialética: discurso e ação, teoria e prática, fazer e resistir, sendo práxis educativa. Ensinar e aprender exige alegria e esperança. Decidir é romper e para isso é preciso correr riscos: "o educando que exercita sua liberdade ficará tão mais livre quanto mais eticamente vai assumindo a responsabilidade de suas ações" (FREIRE, 2014, p. 93).

A mediação pedagógica estabelece uma relação positiva consigo mesma, com os outros, sem julgamentos de valores. Os profissionais de educação têm que ter muito cuidado em relação ao outro para não criar rótulos, a nossa relação com o outro precisa ser pedagógica, ela precisa ser com cuidado pedagógico. $\mathrm{O}(\mathrm{a})$ educador(a), quer seja ele pedagogo(a), historiador(a), educador(a) físico(a), geógrafo(a), deve ter em mente que está lidando com seres humanos, e conforme aponta PIMENTA (1996) está efetivando um processo de humanização, e tal processo requer ética, respeito e amorosidade. Concordamos com FREIRE, quando salienta que:

A curiosidade do estudante às vezes pode abalar a certeza do professor. Por isso é que, ao limitar a curiosidade do aluno, a sua expressividade, o professor autoritário limita a sua também. Muitas vezes, por outro lado, a pergunta que o aluno livre para fazê-la, faz sobre um tema, pode colocar ao professor um ângulo diferente, do qual lhe será possível aprofundar mais tarde uma reflexão mais crítica. (FREIRE, 2011, p. 44).

Neste sentido, não podemos culpar o(s) outro(s), carregar os pré-conceitos, precisamos lidar com as diferenças, mas que não pode ser adversa ao bem-estar da coletividade, da nossa Casa Comum, a Terra (Boff, 2012). Não podemos esquecer a nossa postura e competência enquanto, profissionais da educação. Uma sala de aula não deve ser um território de poder desigual, onde educador e educando se confrontam, mas, pelo contrário, é na interação um 
com o outro que a educação, o conhecer e os métodos ao fazer se fortalecem pela interação dialógica.

O educador não é o centro dos saberes e nem são absolutos, assim como os educando não são tábuas rasas (FREIRE, 2014). O inquietar frente ao que se presencia, vivencia ou executa é o pontapé inicial para possíveis modificações e alterações de comportamentos, pois nos faz refletir ao gerar uma situação-problema, que somos capazes de resolver ao desacomodar. É necessário romper com as formas de ensinar que são padronizadas ao fazer e seguir fórmulas determinadas, refletir e questionar são necessários ao fazer.

Atualmente, vivenciamos novos tempos da sociedade: tecnologias digitais; emancipação feminina; novas construções familiares; posicionamentos dos educandos em sala de aula e em outros espaços ao questionar e não aceitar respostas prontas. Enfim, todo esse emaranhado de situações novas contribui para um novo (re)pensar sobre as práticas pedagógicas e os papéis dos profissionais da educação. As peculiaridades precisam fazer e ser parte ao construir as propostas pedagógicas a partir das expectativas e interesses dos educandos. Os papéis dos professores de educação física, historiadores e pedagogos(as) são parar além de corrigir atividades, nós ajudamos a enfrentar e lidar com situações problemas, ou seja, não é apontar as falhas, mas fortalecer as parcerias pelo coletivo ao (re)fazer os papéis dialogicamente: educandos e educadores.

Alguns elementos são fundamentais para a mediação pedagógica, são eles: a o diálogo, a flexibilidade, o respeito, a confiança, a relação de apoio, a superação, a escuta e a reflexão. Então, ser profissional da educação é um processo de constituição permanente pela identidade docente, por exemplo: na graduação tivemos os primeiros elementos que são os saberes, mas no decorrer foi necessário desenvolver as competências que é a mediação pedagógica em diferentes ambientes. Nós educadores não ficamos apontando o dedo, pois estamos cientes que outros três apontam para nós, por isso a escrita foi fortalecida com tantas mãos. Nós profissionais da educação apostamos nas rodas de discussões que integram o coletivo e possibilita (re)pensar as possibilidades pela e com a mediação pedagógica.

O entrelace problematizado ao longo da escrita abordou perspectivas: o papel do professor de educação física, do pedagogo e do historiador, considerando que ambos precisam mediar os conhecimentos ao compartilhar os saberes entre educandos e educadores. Ser profissional da educação só acontece no exercício permanente da atuação docente, através da dialogicidade e das reflexões coletivas ao refletir e traçar caminhos para uma educação mais 
justa e igualitária para a sociedade. A formação teórica e prática do pedagogo, do educador físico e do historiador são indispensáveis para o exercício da docência, já que concluir a graduação é o primeiro passo, para obter a base necessária, mas, a formação precisa ser permanente.

\section{Conclusões}

Ser pedagogo, educador físico e historiador só acontece no exercício permanente da atuação docente, por meio da dialogicidade e das reflexões que precisam ser coletivas ao refletir e traçar caminhos para uma educação mais justa e igualitária para a sociedade. Não tem relação apenas com as metodologias de ensino, mas com as posturas, com as práticas pedagógicas que precisam ser mediadoras. A formação permanente tanto do pedagogo, quanto do historiador e/ou professor de educação física são indispensáveis para o exercício da docência, já que concluir a graduação é o primeiro passo, mas não podemos parar.

O que justifica nossa escolha por continuar a formação no PPGEA. Somos educadoras ambientais que dialogam e refletem sobre a educação. Percebemos pelo tempo histórico da nossa formação que a educação recebe significados diferentes na medida em que a compreensão sobre ela é desenvolvida. Compreendemos que a formação dos profissionais da área da educação deve ser continua, na medida em que o educador se posiciona diariamente como aprendente ao dialogar com os educandos. Somos sujeitos históricos e é na formação permanente que (re)significamos as aprendizagens e partilhamos saberes no âmbito planetário.

\section{Referências}

BOFF, Leonardo. As quatro ecologias: ambiental, política $e$ social, mental $e$ integral/Leonardo Boff. - Rio de janeiro: Mar de ideias: Animus Anima, 2012. 56 p. (Obra completa)

FREIRE, Paulo. Ação cultural para a liberdade e outros escritos. 14.ed. rev. anual. Rio de Janeiro: Paz e Terra, 2011. 259 p. (Obra completa)

FREIRE, Paulo. Pedagogia da Autonomia: Saberes Necessários à Prática Educativa. 43. Edição. São Paulo: Paz e Terra, 2011. 144 p. (Obra completa) 
FREIRE, Paulo. Pedagogia do Oprimido. 56 ed. Ver e atual- Rio de Janeiro: paz e terra, 2014. 253 p. (Obra completa)

FREIRE, Paulo. Por uma pedagogia da perguntal Paulo Freire, Antonio Faundez. Rio de Janeiro: Paz e Terra, 1985. 251 p. (Obra completa)

PIMENTA, Selma Garrido. Formação de professores - saberes da docência e identidade do professor. Revista da Faculdade de Educação, [S.1.], v. 22, n. 2, p. 72-89, jan. 1996. ISSN 1806-9274. Disponível em: http://www.revistas.usp.br/rfe/article/view/33579. Acesso em: 10 set. 2019. (Artigo em Periódico Digital) 